\title{
A EFETIVIDADE DOS PROGRAMAS DE EDUCAÇÃO FISCAL E DA NOTA FISCAL PAULISTA NA CONSTRUÇÃO DA CIDADANIA E NO CRESCIMENTO DA ARRECADAÇÃO TRIBUTÁRIA
}

THE EFFECTIVES OF THE FISCAL EDUCATION PROGRAMS AND THE

PAULISTA TAX NOTE IN THE CONSTRUCTION OF CITIZENSHIP AND THE

GROWTH OF TAX COLLECTION

Amery Moisés Nadir Júnior

Doutorando em Administração na Universidade do Vale do Itajaí (Biguaçu/Brasil). Auditor Fiscal da Receita Estadual

de Santa Catarina (Florianópolis/Brasil). E-mail: amerymnj@gmail.com.

\section{Denise Del Prá Netto Machado}

Doutora em Administração de Empresas pela Fundação Getúlio Vargas (São Paulo/Brasil). Professora titular no Programa de Pós-Graduação em Administração da Universidade do Sul de Santa Catarina (Palhoça/Bra-

sil). E-mail: profadenisedelpra@gmail.com.

\section{Eduardo Guilherme Nuncio}

Mestrando em Administração pela Universidade do Vale do Itajaí (Biguaçu/Brasil). Empresário (Itajaí/

Brasil).E-mail: egnuncio@me.com.

\section{Manuel Fernandes Neto}

Mestrando em Administração na Universidade do Sul de Santa Catarina (Palhoça/Brasil). Empresário (São José/Brasil). E-mail: m.fernandesneto@yahoo.com.br. 


\section{RESUMO}

Este artigo resulta da investigação sobre a efetividade dos Programas Nacional de Educação Fiscal (PNEF) e Nota Fiscal Paulista (NFP), implementados como instrumentos de construção da cidadania, sob a ótica da responsabilidade social e da ambivalência moral. É resultado, ainda, da análise quanto à efetividade da NFP para o crescimento nominal da arrecadação com o ICMS (imposto sobre circulação de mercadorias e prestação de serviços de transporte e comunicação) nos estados de São Paulo, Santa Catarina e demais estados brasileiros, no período de 2009 a 2016. Trata-se de pesquisa bibliográfica, descritivo-exploratória, para a qual se utilizou de estatística descritiva no tratamento e na apresentação dos dados secundários, relacionados à arrecadação tributária. Os resultados obtidos levaram à constatação de que, enquanto o PNEF promove a construção da cidadania, com base na moral da integridade; a NFP incentiva o patrimonialismo e o particularismo, com base na moral do oportunismo, privilegiando a camada mais rica da população em detrimento das mais pobres. Além disso, a NFP acaba por reduzir o montante do repasse constitucional do ICMS aos municípios, à Administração, direta e indireta, e aos demais Poderes. Demonstraram, também, por meio de gráficos, a ausência de efetiva contribuição da NFP para o crescimento nominal com o ICMS no estado de São Paulo.

Palavras-chave: Ambivalência moral. Arrecadação tributária. Programa de Educação Fiscal. Programa Nota Fiscal Paulista. Responsabilidade social.

\section{ABSTRACT}

This article investigated the effectiveness of the National Fiscal Education Programs (PNEF) and the Nota Fiscal Paulista Program (NFP) as tools for building citizenship, from the point of view of social responsibility and moral ambivalence. The article also analyzed the effectiveness of NFP for the nominal growth of ICMS collection (tax on goods circulation and provision of transportation and communication services) in the states of São Paulo, Santa Catarina and other Brazilian states, in the period from 2009 to 2016. This is a descriptiveexploratory bibliographical research, with the use of descriptive statistics for treatment and presentation of secondary data related to tax collection. The authors of this article found that while the PNEF promotes the construction of citizenship based on moral integrity, the NFP encourages patrimonialism and particularism based on the morality of opportunism, privileging the richest section of the population to the detriment of the poorest. In addition, the NFP ends up reducing the amount of the ICMS constitutional transfer to the municipalities, to the Administration, direct and indirect, and to the other Powers. Graphs have also shown the absence of effective contribution of NFP to nominal growth with ICMS in the state of São Paulo.

Keywords: Moral ambivalence. Nota Fiscal Paulista Program. Social responsability. Tax collection. Tax Education Program. 


\section{INTRODUÇÃO}

O Poder Público, para cumprir com suas finalidades constitucionais, garantindo direitos coletivos e individuais e prestando serviços adequados aos cidadãos, necessita de recursos financeiros. Nesse sentido, depende, principalmente, da arrecadação de tributos (receitas públicas derivadas), em especial dos impostos. Outra forma de ingresso de recursos são as receitas patrimoniais (receitas públicas originárias), de menor representatividade, se comparadas às receitas tributárias (COSTIN, 2010). Nos estados brasileiros e no Distrito Federal (DF), o principal tributo é o ICMS (imposto sobre operações relativas à circulação de mercadorias e sobre prestações de serviços de transporte interestadual, intermunicipal e de comunicação), responsável pela arrecadação de 412 bilhões de reais no exercício de 2016 (CONFAZ, 2016), representando 6,57\% do Produto Interno Bruto (PIB) nacional, que atingiu, em valores correntes, 6,266 trilhões de reais (IBGE, 2016). No mesmo exercício, a carga tributária bruta, considerando a totalidade dos tributos no Brasil, atingiu 32,38\% do PIB (CETAD, 2016).

Não obstante, o Brasil enfrenta o problema da elevada evasão tributária, estimada pela Tax Justice Network (2011) em 280 bilhões de dólares, a partir de estudo que considerou dados de 145 países (anobase 2010), como PIB, população, gastos públicos, economias formal e informal, bem como a carga tributária. Em termos absolutos, o Brasil ocupa o segundo lugar em perdas com evasão fiscal, enquanto os Estados Unidos ocupam o primeiro lugar, com 337 bilhões de dólares. Nessa comparação, porém, devese levar em conta o fato de o PIB americano ser quase sete vezes superior ao PIB brasileiro à época do estudo (TAX JUSTICE NETWORK, 2011). No combate à evasão de tributos, as administrações tributárias brasileiras, em geral, utilizam medidas como a simplificação da legislação tributária, a adoção de métodos preventivos de fiscalização, a inovação nas sanções punitivas (cobrança dos tributos com multa e juros), a aplicação de sanções premiais (incentivos de natureza tributária e financeira) e o fomento a programas de Educação Fiscal (MANGIERI, 2015; SEVEGNANI, 2009).

A simplificação da legislação tributária proporciona ao contribuinte uma melhor compreensão das normas e maior facilidade no recolhimento dos tributos, enquanto a intensificação da fiscalização tributária aumenta a percepção de risco por parte do contribuinte fraudador, especialmente com o cruzamento de dados e o monitoramento contínuo dos grandes contribuintes (SEVEGNANI, 2009). No âmbito das sanções premiais, empregadas pelo Poder Público para estimular condutas no meio social, encontram-se os benefícios fiscais, que reduzem o gravame dos tributos, e os programas de premiação, como a Nota Fiscal Paulista (NFP), que concede créditos financeiros aos consumidores pela obtenção de notas fiscais nas aquisições de bens, mercadorias e serviços. Porém, os efeitos positivos das sanções premiais podem ser efêmeros, requerendo, da parte do Estado, a aplicação de medidas educacionais que estimulem, no 
cidadão, a compreensão das condutas fomentadas do ponto de vista ético e moral e não o interesse em recompensas econômicas (GRACCO; SILVA, 2014).

É neste sentido que a Educação Fiscal se constitui como instrumento de política pública para a construção da cidadania. Somente por meio da conscientização e do fortalecimento da percepção moral da função socioeconômica dos tributos para a sociedade e do controle participativo da aplicação dos recursos públicos (PACHECO FILHO, 2013; SAINTZ DE BUJANDA, 1967) que se construirá a cidadania, sendo as queixas sobre a deficiente moralidade tributária dos cidadãos meros reflexos da deficiente moral fiscal do Estado, ou seja, um fenômeno implica outro (TIPKE, 2012). Portanto, é preciso que o recolhimento dos tributos seja abordado através da lente da responsabilidade social corporativa, com as administrações tributárias adotando medidas que viabilizem o diálogo entre os contribuintes e o Fisco (BENNETT, 2011).

É exatamente nesse item que esta pesquisa se justifica, pois, apesar da Educação Fiscal exercer papel conciliatório entre o Estado e o cidadão-contribuinte, verifica-se escassez de estudos sobre a cultura fiscal na América Latina (RIVILLAS; LINDEMBERG, 2014) e a Educação Fiscal no Brasil (GRZYBOVSKI; HAHN, 2006). Além disso, para fundamentar o Programa Nacional de Educação Fiscal (PNEF), exploramse, ainda, temas transversais, como controle social, justiça fiscal e cidadania, embora não se estabeleça uma associação desses conceitos a um corpo coordenado, que represente a base subjacente da Educação Fiscal (BORGES; PEREIRA; BORGES, 2015).

A Nota Fiscal Paulista (NFP) foi escolhida para compor esta pesquisa em virtude da sua relevância, tanto em termos de abrangência como de volume de recursos públicos, uma vez que já distribuiu o total de 14,6 bilhões de reais, assim divididos: 13,1 bilhões de reais a título de créditos financeiros; e 1,5 bilhão de reais em premiações via sorteios (SEFAZ/SP, 2017). Ainda não há consenso entre os pesquisadores sobre os efeitos do programa da NFP sobre a arrecadação do ICMS do estado de São Paulo, a exemplo do estudo realizado por Mattos, Rochay e Toporcov (2013) que considerou o período de 2005 a 2010. Segundo Moraes (2013), parte expressiva dos consumidores não utiliza a NFP diante de dúvidas a respeito da motivação do Programa e dos benefícios em se exigir a nota fiscal por ocasião de suas compras.

Diante do exposto, questiona-se qual a efetividade do Programa Nacional de Educação Fiscal (PNEF) e do Programa Nota Fiscal Paulista (NFP) como instrumentos de construção da cidadania sob a ótica da responsabilidade social, da ambivalência moral e do crescimento nominal das arrecadações, com o ICMS dos estados de São Paulo e de Santa Catarina comparativamente aos demais estados brasileiros?

Para responder a essa questão de pesquisa, foram traçados os seguintes objetivos: a) investigar a efetividade do PNEF e da NFP, como instrumentos de construção da cidadania sob a ótica da responsabilidade social e da ambivalência moral; e b) mensurar a efetividade financeira da NFP por meio 
da comparação do crescimento nominal da arrecadação do ICMS dos estados de São Paulo e de Santa Catarina e do estado de São Paulo com o restante dos estados brasileiros, no período entre 2009 e 2016.

O objetivo da escolha dos estados paulista e catarinense foi possibilitar a comparação de dois extremos opostos: enquanto o primeiro possui programa pioneiro de incentivo à emissão de documentos fiscais eletrônicos no varejo, ou seja, a NFP, o segundo nunca adotou medida semelhante no período considerado (2009 a 2016). Além disso, eles possuem alto nível de industrialização e são os estados mais competitivos do Brasil (RANKING DE COMPETITIVIDADE DOS ESTADOS, 2018).

Estruturalmente, este artigo está organizado com as seguintes seções, além desta introdução: perspectiva teórica, método, análise dos resultados e considerações finais.

\section{PERSPECTIVA TEÓRICA}

\subsection{PAPEL DA EDUCAÇÃO FISCAL NA CONSTRUÇÃO DA CIDADANIA}

No Brasil, a escassez de instrumentos de controle das finanças nos órgãos públicos é um problema antigo (ZIRBES; BITARELLO; STAUDT, 2009), que faz a sociedade exigir cada vez mais transparência nas ações do Estado, obrigando os administradores públicosaadotarem processos de gestão mais democráticos e de maior efetividade (PNEF, 2015). Essas ações podem ser constatadas com a publicação das Leis da Transparência na Gestão Fiscal (Lei Complementar federal n 131/2009) e do Acesso à Informação (Lei federal n 12.527/2011), que estabelecem prerrogativas de acesso público às informações. Contudo, para transformar o Estado e alcançar um nível mais equilibrado de qualidade de vida, a sociedade também precisa ser mais justa, ética e fundada na solidariedade: "A solidariedade social decorre da concepção de uma vivência compartilhada com os demais membros do grupo social, como princípio inerente à razão de existir do Estado." (SEVEGNANI, 2009, p. 215).

Apesar do dever de pagar tributos se relacionar estreitamente com o princípio da solidariedade (RIVILLAS; LINDEMBERG, 2014), a história brasileira retrata a ausência de mentalidade pautada na cidadania fiscal, desde, por exemplo, a descrição dos feitos do Brasil colonial, imperial e republicano sobre a malversação do dinheiro público pelos agentes estatais, ensejando o surgimento de expressões populares como "santo do pau oco" (prática de esconder, na cavidade interna, oca, de imagens de santos católicos, o desvio do minério que deveria ser tributado) (ABRAHAM, 2015).

Para alterar esta realidade, é necessário propiciar ao cidadão conhecimento que the permita compreender o Estado e a função social dos tributos, por meio da educação transformadora, que pressupõe postura ética e coerente com os valores transmitidos pelo diálogo democrático entre educando e educador 
(SEVEGNANI, 2009), moldando, orientando e organizando a trajetória dos indivíduos (CORTELLA, 2015). A educação possibilita aos cidadãos a emancipação - e não o atrelamento - por intermédio do conhecimento crítico e criativo, arma primordial da equalização de oportunidades, já que o indivíduo precisa aprender a aprender e saber pensar, avaliando o processo produtivo e a forma como nele se insere, estabelecendo uma relação orgânica entre a economia e a sociedade (DEMO, 2012).

O direito à educação é considerado um direito social, veiculado por meio do agir positivo do Estado, essencial para o exercício das liberdades e intimamente relacionado com a dignidade da pessoa humana, que é um dos fundamentos do Estado Democrático de Direito (MATTIELLO; SANTOS, 2018). Todavia, conforme Barreto e Andrade (2018), a educação de qualidade vai além de alfabetizar, compreendendo ensinar e reter habilidades cognitivas e socioemocionais, integrando jovens e adultos para caminhar em direção aos objetivos de desenvolvimento humano sustentável traçados pela ONU na Agenda 2030 (ONU, 2015), tais como: conquista de competências e habilidades para o mercado de trabalho, fortalecimento de valores sociais, redução de desigualdades e empoderamento dos mais vulneráveis. Nesse sentido, o conceito de Democracia se reconstrói à medida que se alimenta da educação plena, quando, por meio dos processos educacionais, o indivíduo se torna conhecedor do meio social do qual participa e do papel para o qual será chamado a desempenhar, colaborando, dessa maneira, para a promoção da prosperidade coletiva (CORDEIRO; PEGORARO, 2018).

Na obra clássica "Teoria da Educação Tributária", Sainz de Bujanda (1967) observa que o conceito de educação tributária se insere nesse marco mais amplo do problema educativo, direcionado à realidade político-social da vida tributária. Ocorre, porém, que o cidadão comum não visualiza claramente a relação entre o tributo que é compelido a pagar e os serviços públicos prestados (PACHECO FILHO, 2013). Assim, a resistência aos tributos se deve, em parte, ao distanciamento assumido pelo aparelho técnico-burocrático do Estado, visto que, quando o cidadão o procura em busca de proteção e auxílio e encontra apenas indiferença, descaso ou hostilidade, o pagamento dos tributos se torna cada vez mais penoso (PACHECO FILHO, 2013). Além disso, algumas presunções prejudicam a ética tributária (SAINZ DE BUJANDA, 1967), por exemplo: a) "Fisco-usurpador ou Estado-ladrão": contribuintes tentam justificar suas condutas fraudulentas alegando a falta de honestidade do Poder Público com as receitas tributárias; e b) "contribuinte fraudador": refere-se ao princípio da incredibilidade sistemática por parte do Fisco, no que tange à veracidade das declarações tributárias, demonstrando falta de consideração à personalidade moral do contribuinte.

O complexo normativo tributário nacional, embora de base principiológica considerada avançada e garantista, é um sistema injusto, vez que o Estado arrecada muito, porém, o índice de retorno ao cidadão é pequeno (OLIVEIRA; FEITOSA, 2017). Além disso, o sistema tributário brasileiro é regressivo, pois 
coloca ênfase na arrecadação de tributos indiretos que incidem sobre bens e serviços e tratam todos os contribuintes de forma igual, o que afronta as concepções de justiça com equidade de Jonh Rawls, para o qual a tributação deve ser um instrumento de distribuição de rendas baseado no princípio da capacidade contributiva, e não um instrumento indutor de desigualdades, fato que inverte a lógica da justiça fiscal (OLIVEIRA; FEITOSA, 2017).

Diante disso, revela-se a importância de Educação Fiscal, que abrange não apenas o conhecimento dos tributos, mas também a compreensão da atividade financeira do Estado, desde a obtenção dos recursos, via arrecadação tributária, até a sua aplicação nos serviços e obras públicas, transcendendo questões político-tributárias (OLIVEIRA; FEITOSA, 2017; SEVEGNANI, 2009) e se caracterizando como processo democrático fundamental (RIVILLAS; LINDEMBERG, 2014). Confirma-se, assim, que a Educação Fiscal deve ser considerada como abordagem didática que estimula o indivíduo a desenvolver consciência fiscal, minimizando o conflito da relação entre o cidadão-contribuinte e o Estado-arrecadador (ABRAHAM, 2015).

Entre os temas de destaque da Educação Fiscal, encontram-se: a) tributo como instrumento para promover mudanças e reduzir as desigualdades sociais; b) qualidade da gestão dos gastos públicos; c) orçamento público; d) combate à sonegação, ao contrabando, ao descaminho e à pirataria; e e) participação e controle social (PNEF, 2015). Esses temas caracterizam a Educação Fiscal como um conjunto de conhecimentos e atitudes, que pode influenciar a vida dos cidadãos (BORGES; PEREIRA; BORGES, 2015) ao forjar uma relação entre o Estado e a sociedade, baseada na confiança e na colaboração - e não apenas na coação -, com estratégias de combate à evasão fiscal, complementadas por iniciativas educativas que vinculem o cumprimento tributário e o controle social do gasto público aos valores democráticos e ao exercício da cidadania (RIVILLAS; LINDEMBERG, 2014).

No seu início, a Educação Fiscal era direcionada aos professores e alunos das escolas públicas e privadas, principalmente do ensino fundamental e médio (PACHECO, 2013), porém, muitas eram as dificuldades encontradas, fosse diante dos problemas estruturais nesses níveis de ensino, fosse pela limitação dos grupos de Educação Fiscal no suporte às ações realizadas pelos professores nas escolas (SILVA, 2011). Hoje, a Educação Fiscal amadureceu, preocupando-se mais em estabelecer uma relação entre a Administração Tributária e o cidadão-contribuinte (PACHECO FILHO, 2013) e em proporcionar uma gestão transparente e eficiente dos recursos públicos (REIS; PFITSCHER; CASAGRANDE, 2012). 0 Programa Nacional de Educação Fiscal (PNEF) é executado por órgãos federais, estaduais e municipais, com autonomia para implementar o Programa de acordo com as peculiaridades socioeconômicas, culturais e financeiras de cada um desses entes, abrangendo todos os níveis de ensino e contando com disseminadores de Educação Fiscal (PNEF, 2015). 
Além disso, considerando o seu contexto, no qual a cidadania deve ser entendida como conjunto de deveres e direitos relativos à participação na condução dos negócios públicos (PACHECO FILHO, 2013) e considerando a ênfase na construção da relação de confiança entre o Fisco e o contribuinte, o PNEF tem como premissa não se vincular a campanhas promocionais, baseadas na distribuição de recompensas financeiras em contrapartida pela obtenção de notas fiscais nas compras de bens e serviços (EDUCAÇÃO FISCAL, 2016).

\subsection{O PROGRAMA NOTA FISCAL PAULISTA COMO SANÇÃO PREMIAL}

Ao lado das normas de comando e controle (sanções punitivas), coexistem as normas de estímulo e prêmio (sanções premiais), que buscam assegurar a adequação dos comportamentos dos contribuintes às exigências da legislação tributária (GORON, 2015). A Nota Fiscal Paulista (NFP), criada pela Lei estadual n 12.685, de agosto de 2007, caracteriza-se como um programa de sanção premial, baseado em sorteios de prêmios e na concessão de créditos financeiros, operando com mais de um milhão de contribuintes varejistas do ICMS e mais de dezoito milhões de participantes cadastrados (SEFAZ/SP, 2017), abrangendo, inicialmente, os restaurantes, e, posteriormente, os demais setores econômicos (MATTOS; ROCHAY; TOPORCOV, 2013).

A Secretaria da Fazenda do Estado de São Paulo (Sefaz/SP), contudo, define a NFP como um "programa de estímulo à cidadania fiscal", que objetiva induzir consumidores a exigirem a nota fiscal por ocasião de suas compras, mediante o oferecimento das seguintes recompensas (SEFAZ/SP, 2017): a) distribuição de até $20 \%$ do ICMS recolhido pelo estabelecimento comercial na forma de créditos financeiros para abatimento do valor do IPVA (imposto sobre a propriedade de veículos automotores) ou transferência dos valores para conta bancária do consumidor; e b) participação em sorteios de prêmios em dinheiro. 0 Programa distribuiu aos consumidores, até fevereiro de 2018, o total de 15,8 bilhões de reais na forma de créditos financeiros ( 14,2 bilhões de reais) e prêmios mediante sorteios (1,6 bilhão de reais), sem computar os custos financeiros de manutenção do sistema da NFP (SEFAZ/SP, 2017).

A NFP tem sido objeto de estudos e de entendimentos controversos, atraindo defensores e críticos. Segundo Gracco e Silva (2014), apesar do caráter educacional da sanção premial ser intrínseco, uma vez que gera no indivíduo - ainda que de forma tênue e indireta - a compreensão da natureza benéfica da ação premiada, o seu efeito pode ser efêmero, pois, mesmo tendo percebido a importância da ação premiada, o beneficiário pode não a considerar como diretriz de ações futuras. Assim, para que os efeitos das sanções premiais sejam constantes e evitar a utilização contínua do instrumento, é essencial o seu fortalecimento 
via medidas educacionais que proporcionem a compreensão e o cumprimento da conduta estimulada por imperativo ético e não apenas econômico (GRACCO; SILVA, 2014).

Quanto ao impacto da NFP na arrecadação com o ICMS, Mattos, Rochay e Toporcov (2013) constataram efeito positivo no crescimento real da arrecadação, no setor terciário paulista (entre 5\% e $10 \%$ ), comparativamente a outros estados. No entanto, não constataram efeito significativo sobre o crescimento real da arrecadação do ICMS, se considerada a totalidade dos setores econômicos, com crescimento médio de $23 \%$ no estado de São Paulo e de $24 \%$ nos estados que não adotam o modelo da NFP. Ainda segundo esses autores, as razões desse resultado limitado podem estar na evasão tributária, supostamente menor no estado paulista em relação aos demais estados, além do fato de os consumidores deixarem de solicitar notas fiscais por conta de filas, constrangimentos ou receios de cruzamentos de dados pela Receita Federal.

Estudo de Paschoal (2012) analisou o funcionamento, a construção e as estratégias regulatórias utilizadas na NPF, concluindo que se trata de um programa popular, complexo e controverso, envolvendo diversos atores que se relacionam de diferentes formas, utilizando-se de estratégias genéricas para atingir seu objetivo, isto é: sanções premiais (sorteios de prêmios e créditos financeiros) e sanções punitivas (multas e sanção reputacional). Para ele, os prêmios seriam as "cenouras" oferecidas pela NFP, que visariam não apenas a indução do comportamento do consumidor uma única vez, mas também "educá-lo" a solicitar a nota fiscal nas compras. Paschoal (2012), embora não conclua se as "cenouras" da NFP, efetivamente, mudaram o comportamento dos consumidores, sugere que houve acréscimo na emissão de notas fiscais não apenas pelas sanções premiais, pois o Programa também prevê punições aos infratores.

Manifestando-se, também, o Sindicato dos Agentes Fiscais de Rendas do Estado de São Paulo posiciona-se contrário à NFP, apontando algumas impropriedades (SINAFRESP, 2016): a) incoerência no fato do Estado devolver dinheiro arrecadado com o ICMS aos consumidores participantes do Programa, quando deveria prestar serviços, minimamente, adequados à população; e b) considerando a escassez dos recursos públicos e as demandas sociais sem atendimento, é injusto o caráter regressivo da NFP, que privilegia as pessoas de maior poder aquisitivo, que são aquelas que compram mais mercadorias e de maior valor agregado, e, por consequência, obtêm mais créditos financeiros e bilhetes de sorteios.

Além disso, segundo estudos de Theodoro (2012) e Gomes (2014), a Sefaz/SP contabiliza a distribuição de créditos financeiros e os sorteios da NFP como se tivessem natureza de imposto pago a maior, procedimento contábil que reduz a receita bruta tributária, afetando negativamente o repasse constitucional do ICMS arrecadado aos municípios, à Administração, direta e indireta, e aos demais Poderes, resultando no repasse, a menor, de cerca de dois bilhões de reais para as universidades estaduais 
paulistas, entre 2008 e 2013. Advertem os referidos autores que não se trata de restituiç̧ão de tributos, uma vez que o fenômeno tributário ocorreu e nasceu da obrigação tributária, extinta com o pagamento do imposto, devendo a distribuição dos créditos financeiros e de prêmios ser contabilizada como despesa, que não afetaria o repasse constitucional do imposto.

No estado de Santa Catarina - que é o segundo estado mais competitivo do Brasil, ficando atrás apenas do estado de São Paulo (RANKING DE COMPETITIVIDADE DOS ESTADOS, 2018) - a Secretaria de Estado da Fazenda tem se posicionado contrária à adoção de programas de sanções premiais em seu território, especialmente, pelo seguinte (GAVAZZONI, 2015): a) expansão do regime de substituição tributária concentra a cobrança do ICMS na indústria e no importador, enfraquecendo o modelo da NFP; b) as operadoras de cartão de crédito e débito fornecem informações ao Fisco, permitindo a cobrança do ICMS, mesmo que o varejo deixe de emitir a nota fiscal; c) alto custo de manutenção do modelo da NFP; e d) os programas que premiam o consumidor por exigir nota fiscal promovem a ideia de "levar vantagem em tudo", comprometendo o desenvolvimento da cidadania fiscal.

\subsection{A RESPONSABILIDADE SOCIAL NAS ORGANIZAÇÕES PÚBLICAS E PRIVADAS}

O discurso sobre ética nas organizações enfatiza a ideia de responsabilidade diante das expectativas da sociedade e dos complexos dilemas morais, confrontados em vários níveis (GRIESSE, 2003). A origem dessas discussões remonta ao final do século XIX e início do século XX (ALVES, 2003), tratando primeiro das atividades filantrópicas e depois abarcando os direitos humanos, o meio ambiente, o combate à corrupção e a defesa do consumidor (ISO, 2009). A obra de Howard R. Bowen, "Responsabilidades Sociais do Homem de Negócios", de 1953, marcou o início da análise criteriosa sobre a responsabilidade social (ALVES, 2003), trazendo à discussão as obrigações dos homens de negócios em observarem linhas de ação compativeis com os fins e valores de sociedade (BOWEN, 1957). À época, a responsabilidade social da empresa era um misto de obrigação e dever social, relacionados à integridade moral (ALVES, 2003).

A ideia de negócios suportando as responsabilidades da empresa com a sociedade e as partes interessadas (stakeholders), além dos acionistas (shareholders), ganhou impulso na década de 1960, despertando a atenção tanto da comunidade acadêmica quanto das grandes corporações, que adotaram o termo responsabilidade social corporativa (RSC) (GRIESSE, 2003). No Brasil, foi na segunda metade da década de 1990 que a RSC começou a chamar maior atenção (GRIESSE, 2003), destacando-se o trabalho do Instituto Ethos, uma Organização da Sociedade Civil de Interesse Público (OSCIP), criada em 1988, com o objetivo de auxiliar empresas a gerirem seus negócios, de forma socialmente responsável e sustentável (ETHOS, 2016). 
A RSC pode ser conceituada como a postura da organização orientada por ações que contribuem para a melhoria da qualidade de vida da sociedade realizadas em decorrência da atenção dispensada às partes interessadas e com as quais interage a fim de satisfazê-las por meio de suas atividades (ESTIGARA; PEREIRA; LEWIS, 2009). Desse modo, o diálogo sobre a aderência à RSC tem se modificado de simples justificações relacionadas à obtenção de resultados financeiros para sofisticadas visões a respeito de resultados sociais (WANG et al., 2016), estabelecendo ligações sistêmicas entre as ações empresariais e suas consequências na existência das organizações, na vida das pessoas e da comunidade, projetando-se para além do argumento clássico que a considerava como mera obrigação (ALVES, 2003).

Carroll (2000) desenvolveu um modelo de RSC composto das seguintes responsabilidades, baseadas em princípios éticos: a) responsabilidade econômica para obtenção de rentabilidade; b) responsabilidade legal para cumprir as normas da sociedade; c) responsabilidade ética para fazer o que é certo, justo e leal; e d) responsabilidade filantrópica para contribuir com propósitos educacionais, sociais, culturais e recreacionais. O modelo procura superar a ideia de que os negócios podem focar em lucros ou em interesses sociais, mas não nos dois ao mesmo tempo, pois os negócios podem ser simultaneamente rentáveis e éticos.

Todavia, apesar da contribuição das organizações públicas e privadas na geração de progresso econômico e de bem-estar social, a atuação de várias delas gera efeitos indesejáveis (externalidades negativas), como poluição ambiental, danos à saúde, desvios na ordem de conduta moral e abusos do poder econômico (ALVES, 2003). Nesse sentido, é necessário que a governança corporativa se alie à RSC e à sustentabilidade, a fim de aprimorar os já existentes ou criar novos mecanismos de gestão (ARAÚJO; RUSSO, 2008), relacionando-os com a implementação de políticas públicas para a promoção do desenvolvimento sustentável (ESTIGARA; PEREIRA; LEWIS, 2009) e orientando condutas nas situações em que as leis não podem, efetivamente, resolver os problemas (BENNETT, 2011).

O estudo de Theuer (2013), que teve por base a prefeitura do município de Rottenburg am Neckar (Alemanha), concluiu que a Administração Pública pode e deve ter papel ativo na criação e coordenação de projetos de RSC, considerando seu papel ativo na viabilização da interação entre os membros da sociedade. No Brasil, a Constituição Federal prevê a participação dos cidadãos como principal objetivo da democracia (THEUER, 2013). Nesse sentido, o engajamento em observatórios sociais representa uma das formas de ocupar espaços de participação na gestão pública, constituindo-se num instrumento de controle social, contribuindo para accountability nas relações entre o Poder Público e a sociedade (SCHOMMER; NUNES; MORAES, 2012). 


\subsection{A ÉTICA E A MORAL NA ESFERA DA ADMINISTRAÇÃO TRIBUTÁRIA}

A ética envolve o conhecimento dos fatos morais, configurando-se numa ciência ou disciplina teórica que torna inteligiveis os eventos sociais, implicando em escolhas entre o bem e o mal e dizendo respeito aos impactos que as decisões e ações dos agentes sociais provocam uns sobre os outros (SROUR, 2012). A ética também pode ser definida como um conjunto de valores construtivos que leva as pessoas a comportarem-se de modo harmonioso, pois, quando os valores são de natureza ética, as pessoas tendem a adotar posturas éticas, sendo o contrário também verdadeiro (WEIL, 1995).

É comum, porém, se confundir a ética, como corpo de conhecimentos, com os códigos de deveres, os sistemas de normas morais ou as morais determinadas, o que equivale a confundir a medicina com as doenças que ela estuda ou a tomar a psicologia pelos sofrimentos psíquicos que ela observa (SROUR, 2012). A ética também não deve ser confundida com sistema legal, já que as leis nem sempre são embasadas em princípios éticos (ALINK; KOMMER, 2011).

A moral pode ser definida como o conjunto de valores éticos de uma pessoa, que se manifesta por meio de sua conduta (BRIDAY, 2011). Ou seja, enquanto a moralidade se refere à adequação de comportamentos individuais em relação a determinado padrão aceito, a eticidade consiste em investigar os fundamentos desse padrão (PACHECO FILHO, 2013). Portanto, os fatos morais são fatos sociais cuja peculiaridade é espelhar posicionamentos ou juízos de valor que as coletividades adotam diante de certos eventos, relativos no tempo e no espaço, em virtude das múltiplas dinâmicas históricas (SROUR, 2012). Assim, as posições assumidas podem convergir ou divergir entre si, pois o que é certo para alguns pode ser errado para outros, considerando que os juízos sobre o bem e o mal, o certo e o errado, o legítimo e o ilegítimo são socialmente convencionados e compartilhados (SROUR, 2012).

A discussão sobre ética empresarial ganhou força na década de 1980, provocando mudanças de comportamento nas organizações e desenvolvimento de projetos proativos, destinados a evitar o julgamento social negativo sobre as suas atividades (GRIESSE, 2003). Todavia, o interesse pela ética empresarial não é fenômeno isolado, nascido dentro das organizações, e, depois, ampliado para a esfera social; mais que isso, é uma reação à situação econômica, paradoxal com o alastramento da miséria e da degradação ambiental (GRIESSE, 2003). Consequentemente, as responsabilidades éticas abarcam uma variedade de normas, modelos e expectativas de comportamentos, que refletem a preocupação com aquilo que os stakeholders consideram como justo e correto (CARROLL, 2000).

A aderência entre a ética individual e a coletiva é denominada compliance, que significa agir de acordo com regras, pedidos ou comandos, cuja base reside na percepção moral do indivíduo quando exposto aos dilemas éticos (SANTOS; GUEVARA; AMORIM, 2013), caracterizando-se como a "consciência da empresa" 
que the impõe freios inibitórios, como se verifica com qualquer indivíduo que se vigia para não infringir as normas legais (CABETTE; NAHUR, 2013). Não obstante, a exigência de respeitar a lei ou de reconhecer os interesses de outros não é considerada, por muitos, como parte de um programa ético, mas como simples observância às convenções vigentes (GRIESSE, 2003). Deve-se atentar, porém, para o fato de um deslize moral significativo poder colocar em risco o valor das organizações, no que tange à sua parte mais sensivel, que é a reputação (SROUR, 2012). Apesar disso, a ação da maioria das organizações ainda corresponde aos estágios mais elementares do desenvolvimento moral, sendo necessária a colaboração entre os setores da sociedade para desenvolver a ética econômica e organizacional, aplicada à transformação social (GRIESSE, 2003).

Na concepção de Carroll (2000), existem três modelos de moralidade na gestão das organizações: a) gestão imoral - desprovida não apenas de princípios éticos, mas opositora àquilo que é justo e correto; b) gestão moral - decisões de negócios obedecem a padrões de elevada ética ou correção, direcionados ao sucesso, de acordo com a lei e os princípios éticos; e c) gestão amoral - abrange a gestão amoral intencional, caracterizada pela crença de que as considerações morais não possuem aplicabilidade nos negócios, e a gestão amoral não intencional, com gestores perseguindo a rentabilidade dentro dos limites da lei, porém não percebendo o prejuízo que suas ações podem causar, sendo suscetível ao aprendizado ético.

Por sua vez, no âmbito individual, para Srour (2012), os valores que orientam as decisões e ações dos indivíduos podem ser assim classificados: a) valores universalistas, que orientam as práticas consensuais, pautadas pela lógica da inclusão, da ética e do altruísmo; e b) valores particularistas, que orientam as práticas abusivas, pautadas pela lógica da exclusão, do egoísmo, particularismo e racionalismo antiético, em que o bem de alguns causa o mal a outros, com poucos se locupletando à custa de muitos.

\subsubsection{A ética e a moral nas relações entre o Fisco e o cidadão-contribuinte}

A moralidade é imposta à Administração Pública ao lado dos princípios da legalidade, impessoalidade, publicidade e eficiência, previstos no artigo 37 da Constituição Federal (BRASIL, 1988). Porém, enquanto o direito natural se baseia em valores morais, no positivismo jurídico de Hans Kelsen, a validade das normas jurídicas independe dos ideais universais da ética, visto que as normas são válidas não porque são boas ou morais, mas por serem criadas por autoridade competente (RIVILLAS; LINDEMBERG, 2014).

Jürgen Habermas se interpõe ao positivismo jurídico na medida em que diverge da questão de que o direito deve ser obedecido simplesmente pela sanção do Estado, defendendo que a lei deve ser cumprida 
em razão de sua legitimidade e dever moral (RIVILLAS; LINDEMBERG, 2014), considerando que a lei, sem suporte moral, é letra morta (FONSECA, 1993). Segundo Carroll (2012), a lei deve refletir a ética codificada na sociedade, incorporando as noções básicas de equidade ou negócios justos.

A relevância desses debates entre Direito e Moral representam o fundamentum de passagem de uma concepção jusfilosófica para uma concepção juscientífica, a qual ora busca se desligar da filosofia, ora busca se aproveitar dela, em especial quando se leva em consideração o papel regulador do Estado e a evolução do funcionamento da Administração Pública (SENHORAS; SENHORAS, 2018). Assim, é possível evidenciar a existência de diferentes matrizes jusfilosóficas que influenciam a Administração Pública e que, por conseguinte, repercutem na consolidação de determinados padrões éticos focados na justiça material ou na justiça formal, considerando as diferentes relações instrumentais entre Direito e Moral, estruturadas em cada período histórico (SENHORAS; SENHORAS, 2018). Não obstante, assevera Teles (2017), é necessário viver a máxima jus est ars boni et aequi, ou seja, o Direito é a arte do bem e do justo.

A legitimidade fiscal também não seria alcançada apenas pelo atendimento das regras positivadas, mas, sobretudo, pela observância da ética, seja na instituição do tributo, seja na sua cobrança, resultando na sua aceitação natural pela sociedade, independentemente do patamar do gravame tributário (MACEI, 2012). A ética tributária representa a teoria do agir moral-impositivo dos Poderes Públicos e do agir moraltributário do cidadão-contribuinte (TIPKE, 2012), com o princípio da moralidade tributária informando as relações entre eles (PACHECO FILHO, 2013).

O conceito de moralidade tributária faz referência às normas que determinam o comportamento virtuoso dos contribuintes a respeito das obrigações para com o Estado (BRIDAY, 2011). Contudo, não se deve confundir a regra de moral com a regra de direito, pois esta é dotada de sanção no caso de seu descumprimento, enquanto aquela é questão de foro íntimo, sujeita apenas à reprovação social (PACHECO FILHO, 2013).

A moralidade tributária do Estado se funda num conceito de justiça, como a igualdade de todos perante a lei, o que, no Direito Tributário, assume a forma de igualdade na repartição da carga tributária, cabendo observar que o princípio da igualdade não significa tratar a todos da mesma forma, mas tratar a cada um na medida de suas desigualdades (PACHECO FILHO, 2013). Nesse sentido, a postura meramente arrecadatória do Estado revela ofensa à Moralidade Pública tributária, pois, desse modo, não atende aos objetivos de igualdade entre os contribuintes e os aspectos sociais do tributo (MACEl, 2012), fazendo com que o pagamento do tributo seja visto como obrigação a ser minimizada e não como algo a ser influenciado pela moral (BENNETT, 2011).

Resumindo, segundo Macei (2012), a atitude do contribuinte seria o reflexo do exemplo da conduta estatal, pois quando o Estado institui e cobra tributos com justiça e aplica adequadamente os recursos 
deles provenientes, o contribuinte se obriga a fazer sua parte. Portanto, não apenas as ações de cobrança do tributo devem atender aos preceitos morais, mas também as ações do gestor público, do legislador, do magistrado e do próprio contribuinte.

\subsubsection{A ambivalência moral na concessão de benefícios tributários}

Segundo Hohden (1998), a educação moral aponta que as pessoas devem ser boas e deixarem de ser más a fim de evitar castigo e receber prêmio. Porém, tais preceitos são ineficientes para tornar o ser humano realmente bom, pois a ideia de prêmio e castigo baseia-se no egoísmo. Pergunta-se, porém, como se podem substituir tais motivos inéticos de prêmio e castigo? A resposta é que o homem deve ser bom e evitar o mau em virtude de sua própria realização e autoaperfeiçoamento (HOHDEN, 1998). Lembra Andrews (2015) que os neurocientistas ligados à pesquisa sobre ética chegaram à conclusão de que a fundação da moralidade é a empatia, que é a raiz da ética. Portanto, em vez de ensinar regras morais de forma racional, dever-se-ia desenvolver a educação para a empatia (ANDREWS, 2015).

Em sociedades desiguais, como a brasileira, existe uma grande capacidade da parcela mais rica da população, por possuir maior capacidade de obter favores fiscais-tributários dos decisores políticos, afetar as políticas estatais em seu favor, aumentando o montante de recursos desviados das atividades produtivas para as atividades improdutivas dos "caçadores de renda" (RODRÍGUES, 2004). Assim, em qualquer país democrático, nenhum cidadão, muito menos empresa, tem o direito moral de empregar a riqueza privada para influenciar as políticas públicas, muito menos alegar que o governo não deve interferir nos assuntos empresariais, enquanto as empresas interferem nos assuntos do governo (MINTZBERG, 2015).

A teoria dos caçadores de renda enfatiza que a ação dos grupos de pressão está intimamente relacionada à estrutura institucional, geradora do sistema de incentivos dentro da sociedade, por meio da obtenção de concessões de direitos de monopólio, subsídios, isenções, subvenções, reservas de mercado, políticas restritivas e protecionistas, entre outras formas de privilégios (MONZONI NETO, 2001). Exemplo desses privilégios, entre outros, são os programas federais de benefícios fiscais ao setor produtivo, especialmente o industrial, conhecidos como "Bolsa Empresário", que correspondem a 3,4\% do PIB brasileiro (LANDIM, 2016). Segundo Sevegnani (2009), no Brasil, não é comum a concessão de benefícios como resultado de pressões de grupos empresariais, que buscam favorecimento próprio, sem nenhuma justificativa pública. Porém, quando parte dos contribuintes é desonerada das obrigações tributárias em decorrência da fruição de benefícios fiscais, outra parte será onerada com mais tributos para compensar a renúncia de receita (SEVEGNANI, 2009). 
Observa-se, assim, que a teoria dos caçadores de renda possui relação com a ambivalência moral, seja a brasileira ("roupa limpa por fora, roupa suja por baixo"), seja aquela dos demais países latinos, considerando que a ambivalência moral se origina da justiça morosa, da voracidade tributária e, especialmente, das regulamentações do Estado burocrático e cartorial (SROUR, 2012). Nos países católicos, a dupla moral prevaleceu, podendo-se identificar dois tipos de moral opostos (SROUR, 2012): a) moral da integridade (idealista): oficial, pública, universalista e altruísta, apregoando o caráter e a virtude; e b) moral do oportunismo (funcional): oficiosa, clandestina, maliciosa, egoísta e particularista, promovendo arranjos paralegais e práticas dissimuladas. Portanto, esses dois tipos de moral convivem num consórcio insólito, pois são amplamente contraditórios: enquanto a moral do oportunismo é frouxa e inopinada; a moral da integridade é rígida e condiz com as expectativas públicas (SROUR, 2012).

O interesse público é aquele apontado pela lei como sendo o interesse da coletividade, prevalecendo sobre os interesses particulares. Ou seja, há interesse público somente quando a vantagem econômica ou moral é de interesse de toda a comunidade (PACHECO FILHO, 2013). Contudo, as posturas oportunistas são difíceis de serem detectadas, pois ocorrem na penumbra, podendo-se distinguir também dois tipos: a) oportunistas contumazes: dotados de mau-caráter; e b) oportunistas de ocasião: indivíduos geralmente honrados, que, eventualmente, premiados pelas circunstâncias, desviam-se do bom caminho (SROUR, 2000).

Como se percebe, a ambivalência moral consolida a tradição da cultura cívica pouco desenvolvida, baseada no patrimonialismo, cujas normas oportunistas de conduta permitem aos maus costumes tornarem-se morais (SROUR, 2012). Além disso, deve-se considerar que o oportunismo não é mero desvio das normais morais, mas um conjunto articulado para justificar os malfeitos dos tomadores de decisão, que estão acima de toda ética que não seja a ética do lucro: "Só a esta última eles prestam contas" (BAUMAN; BORDONI, 2016, p. 141).

\section{MÉTODO}

Conforme a taxonomia de Vergara (2005), esta pesquisa se classifica como descritivo-exploratória, uma vez que, além de apresentar as características do Programa Nacional de Educação Fiscal (PNEF) e do Programa Nota Fiscal Paulista (NFP), relacionando-as aos conceitos de responsabilidade social, ética e moral e ambivalência moral, aborda um assunto com pouco conhecimento acumulado, que é a Educação Fiscal (BORGES; PEREIRA; BORGES, 2015; GRZYBOVSKI; HAHN, 2006; RIVILLAS; LINDEMBERG, 2014). Procurou-se, também, triangular diferentes fontes de dados e informações para auxiliar na validação da pesquisa (CRESWELL, 2010). 
Assim, utilizou-se, como meio de investigação principal, a pesquisa bibliográfica, empregando dados secundários, publicados em livros, periódicos, jornais, blogs e portais na Internet (VERGARA, 2005), inclusive dados de arrecadação tributária, os quais foram tratados estatisticamente e apresentados em gráficos comparativos. Além disso, empregou-se, subsidiariamente, técnicas estatísticas descritivas para apresentar os dados de arrecadação por meio de gráficos, facilitando a sua interpretação (KAZMIER, 2007).

Os dados da arrecadação com o ICMS foram obtidos no portal na Internet do Conselho Nacional de Política Fazendária (CONFAZ, 2016), abrangendo o período de 2009 a 2016. Para tanto, os procedimentos de pesquisa obedeceram aos seguintes critérios, justificativas e escolhas metodológicas:

a) escolha da variável arrecadação total ao invés da arrecadação do varejo: não há dúvidas que a análise do desempenho do programa da NFP seria mais efetiva se fossem utilizados dados de arrecadação do varejo, em vez da arrecadação total. Contudo, em face da autonomia dos estados em decidir, conforme suas necessidades, quais produtos estarão sujeitos à substituição tributária progressiva (ST) no âmbito de seus territórios, o crescimento ou a queda na arrecadação varejista do ICMS poderia não representar o seu efetivo desempenho. Isso porque, na ST, como regra, a inclusão de determinado produto automaticamente transfere a arrecadação que seria do atacado ou do varejo para a indústria. Sendo assim, optou-se pela utilização do valor total da arrecadação, pois, eventual crescimento no varejo, em decorrência da NFP, poderia não ser representado nos números deste segmento em virtude da constante inclusão de novos produtos na ST, especialmente a partir de 2010;

b) escolha dos estados de São Paulo e de Santa Catarina, do conjunto dos demais estados e do DF, na comparação da arrecadação: o objetivo da escolha dos estados paulista e catarinense foi possibilitar a comparação de dois extremos opostos, ou seja, enquanto o primeiro possui programa pioneiro de incentivo à emissão de documentos fiscais eletrônicos no varejo (NFP), o segundo nunca adotou medida semelhante no período considerado (2009 a 2016). Além disso, como são dois estados com alto nível de industrialização e competitividade, adotou-se como premissa que as influências macroeconômicas afetariam, de maneira equivalente, as suas arrecadações com o ICMS. Porém, como existem inúmeras variáveis regionais que afetam, sobremaneira, o desempenho arrecadatório dos estados (enchentes, secas, crises econômicas, informalidade, instalações de novas empresas), isso poderia ocultar eventual reflexo positivo que a NFP pudesse gerar na arrecadação com o ICMS. Para reduzir a influência dessas variáveis externas entre os dois estados (SC e SP), realizou-se comparativo entre o crescimento nominal da arrecadação do estado de São Paulo e a média de crescimento da arrecadação do restante dos estados e do DF, excluindo o estado paulista. Dessa maneira, esperava-se que eventual crescimento de um ente federado, em determinado ano, fosse compensado com a queda de crescimento de outro, ou crescimento a menor, de forma que a média final representasse o desempenho do país como um todo; e 
c) escolha do período de análise (2009-2016): apesar de a NFP ter iniciado sua aplicação em outubro 2007, com a publicação da Lei estadual n 12.685, de agosto de 2007, somente a partir de 2009 se pode considerar que o Programa ganhou relevância, pois foi quando ele se tornou obrigatório para todos os setores do varejo, nos termos da Resolução SF-49, de agosto de 2007 (SEFAZ/SP, 2017).

\section{APRESENTAÇÃO E ANÁLISE DOS DADOS}

\subsection{A EDUCAÇÃO FISCAL E A NOTA FISCAL PAULISTA COMO INSTRUMENTOS DE CONSTRUÇÃO DA CIDADANIA}

O programa de Educação Fiscal (PNEF) se coaduna com as características da responsabilidade social e da educação para a cidadania, contribuindo para a inclusão, a equidade, a transparência, a participação e o consenso sociais, revelando-se instrumento efetivo e eficiente de política pública. Ademais, os objetivos e as ações do PNEF, ao buscarem o interesse público, valorizarem a cidadania e a consecução do bem comum, promovem a conexão entre os cidadãos e os governos. Nesse sentido, o PNEF está em plena consonância com o pensamento de Demo (2012), segundo o qual o indivíduo precisa aprender a aprender e saber pensar, o que implica condição de avaliar o processo produtivo e sua inserção nele, e estabelecer relação orgânica entre economia e sociedade.

No que tange ao programa da Nota Fiscal Paulista (NFP), considerando-se os princípios que regem a responsabilidade social nas organizações públicas e privadas, este possui características associadas à gestão burocrática, assistencialista, paternalista, populista e caçadora de renda, incompatíveis com o desenvolvimento socioeconômico sustentável e includente de que necessita a sociedade brasileira e que se espera do Poder Público e das empresas. Desse modo, portanto, a NFP contribui para o agravamento da má distribuição de renda no Brasil.

Além disso, tomando por base os princípios da responsabilidade social da Administração Tributária, bem como a função socioeconômica dos tributos, a NFP possui viés regressivo ao beneficiar os cidadãos com maior renda em detrimento da camada de população mais pobre, que possui menor poder de compra, e, por consequência, depara-se com participação reduzida na distribuição de prêmios e créditos financeiros ofertados pela NFP. E mais, a NFP reduz indevidamente o valor do repasse constitucional da cota-parte do ICMS aos municípios, à Administração, direta e indireta, e aos demais Poderes, causando-Ihes prejuízos.

O PNEF, por sua vez, possui viés progressivo ao contribuir para que o tributo seja compreendido como instrumento de viabilização de mudanças e de redução de desigualdades sociais e não como mera imposição legal, com finalidades arrecadatórias. Para tanto, o PNEF compartilha conhecimentos com 
crianças, jovens e adultos sobre a origem e a finalidade dos tributos, incentivando o cidadão a participar, de forma consciente, do processo de arrecadação, aplicação e fiscalização dos recursos públicos.

A NFP vai de encontro aos princípios e conceitos de responsabilidade social desde a concepção do Programa, pois privilegia a camada mais rica da população e não promove a ligação sistêmica entre o cidadão e a empresa, nos moldes da responsabilidade social corporativa (RSC), ou seja, engajando proativamente as partes interessadas na superação dos desafios sociais abrangentes, como o faz o PNEF. Assim, ao incentivar posturas responsáveis por parte dos cidadãos em termos econômicos, legais, éticos e sociais, pode-se dizer que o PNEF se integra aos princípios da RSC, promovendo a interação entre o Estado e o cidadão para o alcance do bem-estar social (CARROLL, 2000; THEUER, 2013). Pode-se afirmar, ainda, que o PNEF propicia ao cidadão o conhecimento necessário para a compreensão do que o Estado representa e da função social dos tributos por meio do papel transformador da educação, que pressupõe postura ética e coerente com os valores transmitidos por meio do diálogo entre educando e educador (SEVEGNANI, 2009).

Considerando os princípios éticos e os valores morais da sociedade atual, constata-se que a NFP estimula a atividade dos "caçadores de renda", agravando a concentração de riqueza na camada da população mais rica com a distribuição de prêmios e créditos em dinheiro provenientes, na verdade, de receitas oriundas do ICMS efetivamente recolhidas aos cofres públicos e que deveriam ser empregadas na consecução de serviços e obras públicas para o benefício de todos (ricos e pobres). Por conseguinte, a NFP adota valores patrimonialistas e particularistas pautados pela lógica da exclusão, do egoísmo e do parcialismo, com o bem de algumas pessoas causando prejuízo a outras, aproximando-se do conceito de gestão imoral.

No que tange à ambivalência moral, a NFP, pela sua natureza egoísta, interesseira e particularista, identifica-se, tanto do ponto de vista do participante do Programa (consumidor) quanto do Poder Público (instituidor), com a moral do oportunismo. Desse modo, apesar da NFP possuir amparo em lei, deve-se ressaltar que nem tudo que é legal é necessariamente moral e vice-versa, pois as normas jurídicas não se confundem com as normas morais (SROUR, 2012).

O PNEF, ao contrário, segue os princípios éticos e os valores morais, inclusive da moral tributária, auxiliando no alcance da legitimidade fiscal, que não é obtida apenas pelo atendimento da legislação, mas, principalmente, pela observância da ética, seja na instituição do tributo, seja na sua cobrança. Na esfera da ambivalência moral, o PNEF se identifica com a moral da integridade (idealista), especialmente pelas suas características de universalidade, altruísmo, interesse público, caráter e virtude cidadãs. 


\subsection{A NOTA FISCAL PAULISTA E OS REFLEXOS NA ARRECADAÇÃO COM O ICMS}

O objetivo maior estabelecido no Programa Nota Fiscal Paulista (NFP) é o de persuadir o cumprimento das obrigações fiscais por parte dos contribuintes varejistas, de forma que eles passem a emitir com regularidade os documentos fiscais (SEFAZ/SP, 2017). Em última instância, até mesmo em virtude dos elevados custos para manutenção do Programa, espera-se que as medidas adotadas consigam trazer algum reflexo positivo na arrecadação com o ICMS no estado de São Paulo. Nesse sentido, esta subseção apresenta o crescimento nominal da arrecadação com o ICMS, no período de 2009 a 2016, dos estados de São Paulo e de Santa Catarina, e do primeiro com o restante dos estados, incluindo o Distrito Federal (DF).

A Figura 1 apresenta gráfico de crescimento nominal da arrecadação total do ICMS, entre 2009 e 2016, dos estados de São Paulo e de Santa Catarina. Note-se que o exercício de 2009 é apenas o anobase para cálculo do crescimento nominal da arrecadação em 2010 e, por esse motivo, não aparece nos gráficos a seguir.

Figura 1 - Crescimento nominal da arrecadação do ICMS em Santa Cataria e São Paulo



Fonte: elaborada pelos autores com base nos dados do Confaz (2016)

Diante dos dados apresentados na Figura 1, durante o período de vigência efetiva da NFP, não é possivel concluir que o Programa trouxe reflexos perceptiveis e contribuiu, efetivamente, para o crescimento nominal da arrecadação com o ICMS do estado de São Paulo, pois o desempenho percentual do estado de Santa Catarina foi sempre superior, exceto nos anos 2012 e 2015. Contudo, a diferença na arrecadação, nos anos de 2012 e 2015, foi de apenas 2,2 pontos percentuais (pp), em 2012; e de 0,7 pp, 
em 2015. Nos demais anos, em que o estado catarinense supera o paulista na arrecadação, a diferença maior foi de 4,1 pp, em 2010; 4 pp, em 2011; 1,2 pp, em 2013; 11,8 pp, em 2014; e 5,4 pp, em 2016.

A Figura 2 apresenta gráfico demonstrando o crescimento nominal da arrecadação com o ICMS, desta vez, porém, comparando o estado paulista com o restante do país (demais estados e DF, incluindo o estado de Santa Catarina).

Figura 2 - Crescimento nominal da arrecadação do ICMS em São Paulo e restante do país

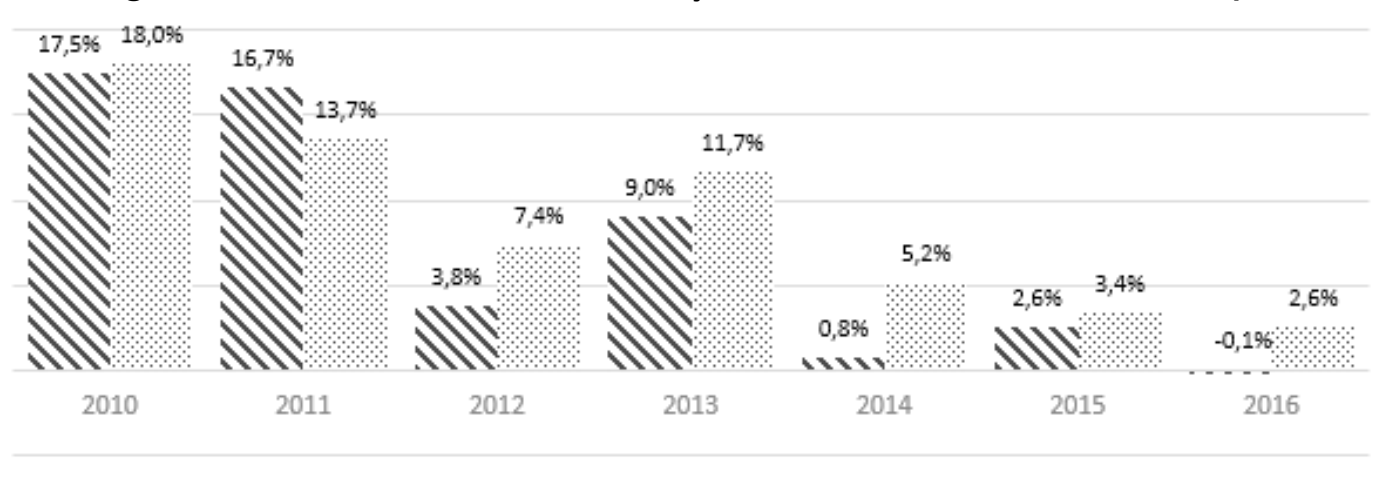

ssP $\because$ Brasil

Fonte: elaborada pelos autores com base nos dados do Confaz (2016)

Como na Figura 1, os dados apresentados na Figura 2 também não permitem identificar influência perceptível de que a NFP tenha contribuído, efetivamente, para o incremento na arrecadação com o ICMS no estado de São Paulo. Em nenhum momento, entre 2009 e 2016, durante a vigência do Programa, 0 desempenho de São Paulo foi superior à média dos demais estados e DF.

\section{CONSIDERAÇÕES FINAIS}

Este estudo buscou responder à pergunta de pesquisa quanto à efetividade do Programa Nacional de Educação Fiscal (PNEF) e do Programa Nota Fiscal Paulista (NFP) na construção da cidadania, sob a ótica da responsabilidade social e da ambivalência moral, e em particular da NFP no que se refere ao crescimento nominal das arrecadações com o ICMS dos estados de São Paulo e de Santa Catarina, comparativamente aos demais estados brasileiros. Assim, observa-se que os objetivos da pesquisa foram alcançados após levantamento do referencial teórico, confrontando-se teorias, conceitos e resultados de 
estudos relacionados ao tema, bem como após a obtenção de dados de arrecadação tributária, trabalhados sob a forma de gráficos comparativos de arrecadação com o ICMS.

Nesse sentido, verificou-se que as atividades do PNEF abrangem a divulgação do conhecimento acerca dos tributos e da atividade financeira do Estado, desde a obtenção dos recursos até sua aplicação nos serviços diretos aos cidadãos e em obras públicas. A Educação Fiscal, assim, transcende as questões de políticas tributárias, estimulando o cidadão a participar ativamente, de forma ética e solidária, na consecução das políticas públicas, contribuindo para a promoção do bem comum, bem como para a construção de uma sociedade mais igualitária.

Quanto aos procedimentos abrangendo a NFP, constatou-se que estão focados, prioritariamente, nos sorteios de prêmios e na distribuição de créditos financeiros como recompensa ao consumidor que exige a emissão de nota fiscal por ocasião de suas compras. Tal procedimento envolve a distribuição de valores bilionários, oriundos da arrecadação com o ICMS, afetando, negativamente, a repartição constitucional da receita tributária com os municípios, Administração, direta e indireta, e demais Poderes. Além disso, conforme se verifica na Figura 2, não foi possivel identificar que a NFP tenha contribuído efetivamente para o incremento na arrecadação do ICMS no estado paulista. Em nenhum momento, entre 2009 e 2016, durante a vigência do Programa, o desempenho de São Paulo foi superior à média dos demais estados.

O Estado de Santa Catarina, tomado como principal exemplo comparativo, posiciona-se contrariamente à adoção de programas de sanções premiais no modelo da NFP, optando pelo combate efetivo à evasão tributária e aos investimentos no seu Programa Estadual de Educação Fiscal. Conforme demonstrado no gráfico comparativo de arrecadação com o ICMS entre os estados de São Paulo e de Santa Catarina (Figura 1), este último obteve desempenho percentual sempre superior ao estado paulista, exceto nos anos 2012 e 2015.

Desse modo, constata-se a relevância do PNEF na construção da consciência do "cidadãocontribuinte", tanto em relação ao papel social dos tributos quanto na participação popular para o controle dos gastos públicos, ao mesmo tempo em que se verifica a existência de inúmeras contradições envolvendo a NFP desde a sua criação, como: afronta aos princípios éticos e morais, ambivalência moral, caráter regressivo na distribuição de renda e consequências negativas na repartição constitucional do ICMS.

Como aspecto de limitação desta pesquisa, destaca-se a dificuldade de acesso a dados oficiais, especialmente os relativos aos custos de criação e manutenção do sistema da NFP e à contabilização dos benefícios a título de despesa com "restituição de tributos". Para pesquisas futuras, sugere-se ampliar a investigação a outros programas de sanções premiais, comparando os dados de crescimento de 
arrecadação com indicadores econômicos de formalidade e informalidade dos estados, considerando as suas potenciais influências nos resultados obtidos com programas do tipo NFP.

\section{REFERÊNCIAS}

ANDREWS, Susan. Por uma vida de verdade: saúde, bem-estar e gerenciamento do estresse. São Paulo: Ágora, 2015.

ARAÚJO, Margarete Panerai; RUSSO, Denise Ries. Governança Corporativa: Novos Mecanismos de Responsabilidade Social e de Sustentabilidade. Revista Gestão e Desenvolvimento, v. 5, n. 1, p. 33-38, 2008. doi: https://doi.org/10.25112/rgd.v5i1.901.

BARRETO, Roberta H. Arcieri; ANDRADE, Diogo de C. Melo. A essencialidade da educação para o alcance dos objetivos da Agenda 2030 para o desenvolvimento humano sustentável. Anais do XXVII Congresso Nacional do CONPEDI. Direitos Sociais e Políticas Públicas I. Porto Alegre - RS, p. 110-125, 2018.

BAUMAN, Zygmunt; BORDONI, Carlo. Estado em crise. Rio de Janeiro: Zahar, 2016.

BENNETT, Catherine. Creando conciencia en el contribuyente: la responsabilidad social corporativa y los foros de diálogo entre contribuyentes y la administración tributaria. Série bibliografia temática. Moral tributária. In: Assembleia Geral do CIAT (Centro Interamericano de Administrações Tributárias), n. 45, Quito, Equador, 2011.

BORGES, Erivan Ferreira; PEREIRA, Jose Matias; BORGES, Gilmara Mendes da Costa. Gestão pública no Brasil: uma proposta de mensuração da educação fiscal do cidadão. Revista de Contabilidade e Organizações, São Paulo, v. 25, p. 3-15, 2015. doi: http://dx.doi.org/10.11606/rco.v9i25.55522.

BOWEN, Howard R. Responsabilidades sociais do homem de negócios. Rio de Janeiro: Civilização Brasileira, 1957.

BRIDAY, Jean Noël. Metodologías para medir la moral tributaria de los contribuyentes y los resultados obtenidos. Série bibliografia temática. Moral tributária. In: Assembleia Geral do CIAT (Centro Interamericano de Administrações Tributárias), n. 45, Quito, Equador, 2011.

CABETTE, Eduardo L. Santos; NAHUR, Marcius T. Maciel. "Criminal compliance" e ética empresarial: novos desafios do Direito Penal Econômico. Porto Alegre: Núria Fabris, 2013.

CARROLL, Archie B. Ethical challenges for business in the new millennium: corporate social responsibility and models of management morality. Business Ethics Quarterly, v. 10, n. 1, 2000. 
CETAD (Centro de Estudos Tributários e Aduaneiros). Carga Tributária no Brasil: análise por tributos e base de incidência. Receita Federal do Brasil, 2016. Disponivel em: <http://idg.receita.fazenda.gov.br/noticias/ascom/2017/dezembro/carga-tributaria-bruta-atingiu-32-38-do-pib-em-2016>. Acesso em: 27 dez. 2016.

CONFAZ (Conselho Nacional de Política Fazendária). Boletim do ICMS. 2016. Disponivel em: < https:// www.confaz.fazenda.gov.br/legislacao/boletim-do-icms>. Acesso em: 26 dez. 2017.

CORDEIRO, Fabiana A. Menegazzo; PEGORARO, Luiz Nunes. A desconstrução do conceito da democracia quantitativa por meio da educação plena: formação cidadã e democracia qualitativa. Anais do XXVII Congresso Nacional do CONPEDI. Direitos Sociais e Políticas Públicas I. Porto Alegre - RS, p. 243-261, 2018.

CORTELLA, Mario Sergio. Pensar nos faz bem!: 1. filosofia, religião, ciência e educação. Petrópolis, RJ: Vozes, 2015.

COSTIN, Claudia. Administração pública. Rio de Janeiro: Elsevier, 2010.

CRESWELL, John W. Projeto de pesquisa: métodos qualitativo, quantitativo e misto. Porto Alegre: Artmed, 2010.

DEMO, Pedro. Pesquisa e construção de conhecimento: metodologia científica no caminho de Habermas. Rio de Janeiro: Tempo Brasileiro, 2012.

EDUCAÇÃO FISCAL. 0 que é Educação Fiscal? Programa de Educação Fiscal - Santa Catarina. Disponível em: http://www.educacaofiscal.com.br/. Acesso em: 28 set. 2016.

ESTIGARA, Adriana; PEREIRA, Reni; LEWIS, Sandra A. Lopes Barbon. Responsabilidade social e incentivos fiscais. São Paulo: Atlas, 2009.

ETHOS (Instituto Ethos de Empresas e Responsabilidade Social). 0 Instituto. Disponivel em: < http:/l www3.ethos.org.br/conteudo/sobre-o-instituto/\#.V_kUyOgrLIU>. Acesso em: 8 out. 2016.

FONSECA, Eduardo Giannetti da. Vícios privados, benefícios públicos?: a ética na riqueza das nações. São Paulo: Companhia das Letras, 1993.

GAVAZZONI, Antonio Marcos. Razões para não termos a Nota Fiscal Catarina. Jornal Metas. 2015. Disponível em: < http://www.jornalmetas.com.br/panorama/razões-para-não-termos-a-nota-fiscal-catarina>. Acesso em: 5 out. 2016. 
GOMES, Rodrigo. Adusp denuncia descontos de $\mathrm{R} \$ 2$ bilhões no repasse às universidades paulistas. Rede Brasil Atual (RBA). 25 mai. 2014. Disponivel em: <http://www.redebrasilatual.com.br/educacao/2014/05/entidade-denuncia-descontos-de-r-2-bilhoes-no-repasse-as-universidades-paulistas-846.html>. Acesso em: 6 out. 2016.

GORON, Henrique Sampaio. Sanção Premial, Normas Indutoras e a Extrafiscalidade Tributária. Revista Páginas de Direito, Porto Alegre, ano 15, n. 1271, 10 de ago. 2015. Disponivel em: <http://www.tex.pro. br/index.php/artigos/316-artigos-ago-2015/7328-sancao-premial-normas-indutoras-e-a-extrafiscalidade-tributaria>. Acesso em: 8 out. 2016.

GRACCO, Abraão Soares Dias dos Santos; SILVA, Marcela Vitoriano e??? As principais sanções premiais no Novo Código Florestal: a superação do dogma kelseniano em direção a uma sociedade resiliente. 2 out. 2014. Disponivel em: <http://www.abraao.com/?tag=as-principais-sancoes-premiais-no-novo-codigo-florestal-a-superacao-do-dogma-kelseniano-em-direcao-a-uma-sociedade-resiliente $>$. Acesso em: 12 out. 2016.

GRIESSE, Margaret Ann. Ética Empresarial e Responsabilidade Social Corporativa à Luz da Teoria de Julgamento Moral, de Lawrence Kohlberg. Impulso, Piracicaba, v. 14, n. 35, p. 33-48, 2003.

GRZYBOVSKI, Denize; HAHN, Tatiana Gaertner. Educação fiscal: premissa para melhor percepção da questão tributária. Revista de Administração Pública - RAP, Rio de Janeiro, v. 40, n. 5, p. 841-64, set./ out. 2006.

HOHDEN, Huberto. Educação do homem integral. São Paulo: Martim Claret, 1998.

IBGE (Instituto Brasileiro de Geografia e Estatística). Indicadores conjunturais. 2016. Disponível em: <http://www.ibge.gov.br/home/estatistica/indicadores/pib>. Acesso em: 26 dez. 2017.

KAZMIER, Leonard J. Estatística aplicada à administração e economia. Porto Alegre: Bookman, 2007.

LANDIM, Raquel. 'Bolsa Empresário' resiste a ajuste no governo Temer e deve custar R $\$ 224$ bi. FoIha de São Paulo. 16 out. 2016. Disponível em: <http://www1.folha.uol.com.br/mercado/2016/10/ 1823160-subsidios-destinados-a-empresas-resistem-a-ajuste-no-governo-temer.shtml>. Acesso em: 16 out. 2016 .

MACEI, Demetrius Nichele. Tributação, moralidade e sustentabilidade. Anais do Universitas e Direito 2012 - PUCPR. doi: 0.7213/UNIVERSITAS.7482.

MANGIERI, Francisco Ramos. Administração tributária municipal: eficiência e inteligência fiscal. Porto Alegre: Livraria do Advogado, 2015. 
MATTIELLO, Darléa C. Palma; SANTOS, Sonia M. Cardozo dos. A Inefetividade das políticas públicas de educação inclusiva no Brasil e sua gênese. Anais do XXVII Congresso Nacional do CONPEDI. Direitos Sociais e Políticas Públicas I. Porto Alegre - RS, p. 126-144, 2018.

MATTOS, Enlinson; ROCHAY, Fabiana; TOPORCOV, Patrícia. Programas de Incentivos Fiscais São Eficazes? Evidência a partir da Avaliação do Impacto do Programa Nota Fiscal Paulista Sobre a Arrecadação de ICMS. Revista Brasileira de Economia - RBE, Rio de Janeiro, v. 67, n. 1, p. 97-120, jan/mar 2013.

MINTZBERG, Henry. Renovação radical: uma estratégia para restaurar o equilíbrio e salvar a humanidade e o planeta. Porto Alegre: Bookman, 2015.

MONZONI NETO, Mario Prestes. Caçadores de Renda: Uma Investigação sobre a Teoria do Rent Seeking. 2001. 121 f. Dissertação (Mestrado em Administração Pública e Governo) - Fundação Getúlio Vargas/ EAESP, São Paulo.

MORAES, Gustavo Hermínio Salati Marcondes de. Adoção de governo eletrônico no Brasil: a perspectiva do usuário do programa Nota Fiscal Paulista. 2013. 164 f. Tese (Doutorado em Administração de Empresas) - Escola de Administração de Empresas de São Paulo da Fundação Getúlio Vargas, São Paulo.

OLIVEIRA, Bruno Bastos de; FEITOSA, Maria Luiza P. de A. Mayer. Os fins e os meios da tributação e do direito tributário: análise a partir da ideia de justiça tributária. Anais do VII Encontro Internacional do CONPEDI. Direito Tributário e Financeiro. Braga (Portugal), p. 266-283, 2017.

ONU (Organização das Nações Unidas). Transformando Nosso Mundo: A Agenda 2030 para o desenvolvimento sustentável. Nova lorque, 2015. Disponivel em <https://nacoesunidas.org/pos2015/agenda2030/>. Acesso em: 28 abr. 2019.

PACHECO FILHO, Velocino. Educação fiscal, relacionamento Fisco-contribuinte e moralidade administrativa. Programa de Educação Fiscal. 2013. Disponível em: <http://www.educacaofiscal.com.br/midia/ artigos.jsp>. Acesso em: 7 out. 2016.

PASCHOAL, Bruno Vinícius Luchi. Punição, recompensa, persuasão e ajuda: Estratégias regulatórias a partir do caso Nota Fiscal Paulista. 2012. 212 f. Dissertação (Mestrado em Direito) - Escola de Direito de São Paulo da Fundação Getúlio Vargas, São Paulo.

PNEF (Programa Nacional de Educação Fiscal). Programa Nacional de Educação Fiscal: Documento base. Grupo Educação Fiscal (GEF). Escola de Administração Fazendária (ESAF). 2015. Disponível em: <http://www.esaf.fazenda.gov.br/assuntos/educacao-fiscal>. Acesso em: 30 set. 2016. 
RANKING DE COMPETITIVIDADE DOS ESTADOS. Relatório Técnico 2018. Disponível em: <http://www. rankingdecompetitividade.org.br/>. Acesso em: 27 abr. 2019.

REIS, Adriano Kozoroski; PFITSCHER, Elisete Dahmer; CASAGRANDE, Maria Denize Henrique. A Educação Fiscal no Brasil: Estudo realizado nos 27 Estados da Federação, distribuídos nas Regiões Norte, Nordeste, Sudeste, Sul e Centro-Oeste. Revista Catarinense da Ciência Contábil - CRCSC, Florianópolis, v. 11, n. 31, p. 37-56, dez./mar. 2012.

RIVILLAS, Borja Diaz; LINDEMBERG, Antonio Henrique. Educación fiscal y construcción de ciudadanía en América Latina. Revista de Estudos Tributários e Aduaneiros, Brasilia-DF, ano I, n. 1, p. 326-354, ago./ dez. 2014.

RODRÍGUES, Francisco. Inequality, redistribution, and rent-seeking. Economics \& Politics, v. 16, n. 3, 2004.

SAINZ DE BUJANDA, Fernando. Teoría de la educacion tributaria. Revista de la Facultad de Derecho de la Universidad de Madrid, n. 24, v. IX, Madrid, 1967.

SANTOS, Renato Almeida dos; GUEVARA, Arnoldo Jose de Hoyos; AMORIM, Maria Cristina Sanches. Corrupção nas organizações privadas: análise da percepção moral, segundo gênero, idade e grau de instrução. Revista de Administração - RAUSP, São Paulo, v. 48, n.1, p. 53-66, jan./fev./mar. 2013.

SCHOMMER, Paula Chies; NUNES, Jonas Tadeu; MORAES, Rubens Lima. Accountability, controle social e coprodução do bem público: a atuação de vinte observatórios sociais brasileiros voltados à cidadania e à educação fiscal. Escola da Advocacia-Geral da União Ministro Victor Nunes Leal. Brasília: EAGU, ano IV, n. 18, p. 229-58, mai. 2012.

SEFAZ/SP (Secretaria da Fazenda do Estado de São Paulo). Nota Fiscal Paulista. Disponível em: < http:/l www.nfp.fazenda.sp.gov.br/default.asp>. Acesso em: 31 dez. 2017.

SENHORAS, Elói Martins; SENHORAS, Cândida A. B. de Magalhães. Ética na Administração Pública Brasileira. Revista Síntese Direito Administrativo, v. 152, p. 1-12, ago. 2018.

SEVEGNANI, Joacir. A resistência aos tributos no Brasil: estado e sociedade em conflito. Florianópolis: Conceito, 2009.

SILVA, José Francisco da. A educação para a cidadania fiscal: Ações do Programa Nacional de Educação Fiscal - PNEF no ensino fundamental e médio. 2011. 78 f. Monografia (Curso de Especialização em Legislativo e Políticas Públicas) - Programa de Pós-Graduação do Centro de Formação, Treinamento e Aperfeiçoamento da Câmara dos Deputados. Brasilia. 
SINAFRESP (Sindicato dos Agentes Fiscais de Rendas do Estado de São Paulo). Hora de repensar o Programa Nota Fiscal Paulista. 20 jun. 2016. Disponivel em: <http://sinafresp.org.br/hora-de-repensar-o-programa-nota-fiscal-paulista/>. Acesso em: 5 out. 2016.

SROUR, Robert Henry. Poder, cultura e ética nas organizações. Rio de Janeiro: Elsevier, 2012.

Ética empresarial. Rio de Janeiro: Campus, 2000.

TAX JUSTICE NETWORK. The cost of tax abuse: a briefing paper on the cost of tax evasion worldwide. Novembro de 2011. Disponivel em: <http://www.taxjustice.net/wp-content/uploads/2014/04/Cost-of-Tax-Abuse-TJN-2011.pdf>. Acesso em: 12 out. 2016.

TELES, Tayson Ribeiro. Uma análise crítica do Direito sob uma perspectiva jusfilosófica. Revista Desafios, v. 4, n. 2, p. 83-95, 2017. Doi: https://doi.org/10.20873/uft.2359-3652.2017v4n2p83.

THEODORO, Gustavo. O Sinafresp e a Nota Fiscal Paulista. Blog do AFR. 19 set. 2012. Disponivel em: $<$ https://blogdoafr.com/articulistas/gustavo-theodoro/o-sinafresp-e-a-nota-fiscal-paulista/>. Acesso em: 6 out. 2016.

THEUER, Daniela. Public Administration and Corporate Social Responsibility: How the State Can Promote Better Social Bonds. Cadernos Gestão Pública e Cidadania, São Paulo, v. 18, n. 63, jul./dez. 2013.

TIPKE, Klaus. Moral tributária do Estado e dos contribuintes. Porto Alegre: Sergio Antonio Fabris Editor, 2012.

VERGARA, Sylvia Constant. Projetos e relatórios de pesquisa em administração. São Paulo: Atlas, 2005.

WANG, Heli et al. Corporate social responsibility: an overview and new research directions. Academy of Management Journal, v. 59, n. 2, p. 534-544, 2016.

WEIL, Pierre. Organizações e tecnologias para o terceiro milênio: a nova cultura organizacional holística. Rio de Janeiro: Rosa dos Tempos, 1995.

ZIRBES, Maria Cristina de Campos; BITARELLO, Jucelaine; STAUDT, Tarcísio. Análise dos Relatórios da Execução Orçamentária e da Gestão Fiscal no Contexto da Lei de Responsabilidade Fiscal. Revista Gestão e Desenvolvimento, v. 6, n. 1, p. 123-136, 2009. doi: https://doi.org/10.25112/rgd.v6i1.936. 